\title{
Elucidating the role of free polycations in gene knockdown by siRNA polyplexes
}

Klauber, Thomas Christopher Bogh; Søndergaard, Rikke Vicki; Sawant, Rupa R.; Torchilin, Vladimir P.; Andresen, Thomas Lars

\section{Published in:}

Acta Biomaterialia

Link to article, DOI:

10.1016/j.actbio.2016.02.021

Publication date:

2016

Document Version

Peer reviewed version

Link back to DTU Orbit

Citation (APA):

Klauber, T. C. B., Søndergaard, R. V., Sawant, R. R., Torchilin, V. P., \& Andresen, T. L. (2016). Elucidating the role of free polycations in gene knockdown by siRNA polyplexes. Acta Biomaterialia, 15(35), 248-259.

https://doi.org/10.1016/j.actbio.2016.02.021

\section{General rights}

Copyright and moral rights for the publications made accessible in the public portal are retained by the authors and/or other copyright owners and it is a condition of accessing publications that users recognise and abide by the legal requirements associated with these rights.

- Users may download and print one copy of any publication from the public portal for the purpose of private study or research.

- You may not further distribute the material or use it for any profit-making activity or commercial gain

- You may freely distribute the URL identifying the publication in the public portal 


\title{
Elucidating the role of free polycations in gene knockdown by siRNA polyplexes
}

Thomas C. B. Klauber ${ }^{1}$, Rikke V. Søndergaard ${ }^{1}$, Rupa R. Sawant ${ }^{2}$, Vladimir P. Torchilin ${ }^{2}$, Thomas L. Andresen ${ }^{1 *}$

${ }^{1}$ DTU Nanotech, Department of Micro-and Nanotechnology, Center for Nanomedicine and Theranostics, Technical University of Denmark, Building 423, 2800 Lyngby, Denmark

${ }^{2}$ Center for Pharmaceutical Biotechnology and Nanomedicine, Northeastern University, Boston, MA 02115, USA

*Corresponding author, e-mail: tlan@nanotech.dtu.dk, Tel.: +45 452581 68, Fax: +45 45887762

\begin{abstract}
Future improvements of non-viral vectors for siRNA delivery require better understanding of intracellular processing and vector interactions with target cells. Here, we have compared the siRNA delivery properties of a lipid derivative of bPEI $1.8 \mathrm{kDa}$ (DOPE-PEI) with branched polyethyleneimine (bPEI) with average molecular weights of $1.8 \mathrm{kDa}$ (bPEI $1.8 \mathrm{kDa}$ ) and $25 \mathrm{kDa}$ (bPEI 25kDa). We find mechanistic differences between the DOPE-PEI conjugate and bPEI regarding siRNA condensation and intracellular processing. bPEI $1.8 \mathrm{kDa}$ and bPEI 25kDa have similar properties with respect to condensation capability, but are very different regarding siRNA decondensation, cellular internalization and induction of reporter gene knockdown. Lipid conjugation of bPEI $1.8 \mathrm{kDa}$ improves the siRNA delivery properties, but with markedly different
\end{abstract}


formulation requirements and mechanisms of action compared to conventional PEIs. Interestingly, strong knockdown using bPEI $25 \mathrm{kDa}$ is dependent on the presence of a free vector fraction which does not increase siRNA uptake. Finally, we have investigated the effect on lysosomal pH induced by these vectors to elucidate the differences in the proton sponge effect between lipid conjugated PEI and conventional PEI: Neither DOPE-PEI nor bPEI 25kDa affected lysosomal $\mathrm{pH}$ as a function of time, underlining that the possible proton sponge effect is not associated with changes in lysosomal $\mathrm{pH}$.

Keywords: Non-viral gene delivery, siRNA, Polyethyleneimine, Proton sponge effect, Polycation

\section{Introduction}

RNA interference (RNAi) based drugs are currently under intense investigation for treating viral infections, cancer and neurological disorders [1]. RNAi is a naturally occurring post-transcriptional gene-silencing mechanism for regulation of gene expression through degradation or translationarrest of the target mRNA [2]. The most extensively described form of RNAi acts through small interfering RNAs (siRNAs), which have very high $(\approx 100 \%)$ sequence similarity with the target mRNA. The siRNAs can be transfected into cells in their short active form or generated intracellularly from longer double stranded RNAs (dsRNAs) [3,4].

The safe and efficient delivery of siRNA specifically to target cells is essential to RNAi-based therapy, but remains a major challenge [5]. Many attempts have relied on modified viruses, which while very efficient - suffer from safety, immunogenicity and scalability issues [6]. As a consequence, non-viral vectors, which are characterized by low host immunogenicity and easy manufacturability, have attracted considerable attention and successful development of a safe and 
efficient non-viral delivery system would be one of the most important achievements in medicine today $[7,8]$.

Cationic polymers are attractive for delivery of siRNA (and DNA) since they are particularly easy to formulate with poly-anionic nucleic acids. The electrostatic interactions between the anionic phosphates in siRNA and cationic moieties in the polymers can assemble the siRNA into nanoparticles - polyplexes - suitable for cellular uptake. Vectors based on polyethylenimine (PEI) were among the first to emerge and are still considered the gold standard in polymer based DNA delivery [9-12] and have also turned out to be efficient siRNA delivery agents in vitro [13-15].

In spite of the huge activity in the field and the broad use of cationic polymers as siRNA delivery agents, several aspects about the mode of action remain unclear. Polyplexes are generally believed to enter the cell via endocytosis, thus a primary research focus has been to ensure endosomal escape to avoid degradation in the lysosomes $[16,17]$ and achieve release of the cargo into the cytosol. One of the key advantages of cationic polymers is their alleged ability to facilitate the so-called proton sponge effect [9], which is believed to be associated with endosomal escape of the polyplexes or their components. In PEI, the many protonated amines facilitate polyplex formation, while the unprotonated amines are able to absorb protons when the complex enters acidic compartments (endosomes and lysosomes). The proton sponge effect is believed to result in excessive V-ATPase mediated $\mathrm{H}^{+}$influx, which leads to increased influx of $\mathrm{Cl}^{-}$and water, and in turn this may lead to osmotic swelling, destabilization and/or rupture of the lysosomal membrane and release of the siRNA into the cytosol [18]. However, the proton sponge effect is debated and incontrovertible experimental evidence remains elusive. An alternative hypothesis is that polyplexes are internalized via the caveolar pathway that bypasses the endolysosomal pathway altogether [19], but the 
existence of a physiologically relevant caveolar pathway with a role in constitutive endocytic trafficking is equally debated [20-22].

One limitation of PEI as a transfection agent has been that both toxicity and delivery efficiency correlates with average molecular weight (MW) [23], and an average MW of $25 \mathrm{kDa}$ is generally considered the upper limit before the toxicity becomes problematic [11]. Several strategies have been devised to preserve the low toxicity of low-MW PEI but improve the delivery capability. One promising approach has been to incorporate hydrophobic moieties onto the polymer amines of e.g. PEI $2 \mathrm{kDa}[24]$ to increase the transfection efficiency, potentially by increasing the interaction of the polymer with the cell membrane. Such a beneficial effect of lipid substitution has been established in the context of plasmid DNA delivery for several cationic carriers $[25,26]$ and more recently for delivery of siRNA [24,27-29].

An important aspect of polycation based gene delivery is the polymer/siRNA ratio necessary to obtain high transfection efficiency. This issue has been addressed thoroughly for PEI mediated DNA transfection [30-32], where it was found that a free (non-condensed) fraction of PEI is very important for achieving high transfection levels. However, as size, electrostatic charge and intracellular compartment of action differ for siRNA compared to DNA, it is not clear how a free fraction of PEI influences gene silencing. For in vivo use, a potential requirement for a free fraction for achieving high gene silencing efficiency is a major obstacle for the use of PEI and other polycations for non-viral gene delivery. Such systems are challenged by the fact that highly cationic entities will interact strongly with anionic blood constituents, the immune system and cells in general, and will therefore not allow for targeting of diseased tissue. In order to rationally develop efficacious siRNA carriers, it is essential that the interplay between the above-mentioned properties are understood. 
In the present study we have compared lipid derivatized bPEI with conventional bPEI $1.8 \mathrm{kDa}$ and bPEI 25kDa. Our PEI derivative is a conjugate of dioleoylphosphatidylethanolamine (DOPE) and bPEI 1.8kDa, which we refer to as DOPE-PEI throughout this text. bPEI $25 \mathrm{kDa}$ serves as a point of reference as delivery efficiency of conventional PEI correlates with average $\mathrm{MW}$ and $25 \mathrm{kDa}$ is widely accepted to be the highest useful average MW before cytotoxicity becomes problematic [11]. We establish to what extent the lipid conjugation alters the condensation properties of siRNA, cellular delivery and silencing of a reporter gene as well as to what extent the lipid conjugation reduces the toxicity of bPEI. We further investigate and compare how PEI and lipid conjugated PEI affect the $\mathrm{pH}$ in the lysosomes, as an increase in lysosomal $\mathrm{pH}$ has been associated with the proton sponge effect. Lastly, we systematically investigate the impact of lipid conjugation to bPEI in relation to the use of excess transfection agent beyond the requirement for full condensation of the siRNA (termed the "free fraction") and the silencing efficiency in comparison to bPEI itself. Although lipid conjugation affects the behavior of PEI and possibly the structure of the particles formed with siRNA, we have chosen to refer to all the used vectors as polymers forming polyplexes.

\section{Materials and Methods}

\subsection{Materials and cell lines}

Branched PEI with a weight-averaged molar mass of $25,000 \mathrm{~g} / \mathrm{mol}(\mathrm{bPEI} 25 \mathrm{kDa}$ ) and 1,800 g/mol (bPEI $1.8 \mathrm{kDa}$ ) were purchased from Sigma-Aldrich (US) and used without further purification. Before use they were dissolved in MQ water to a concentration of $15.4 \mathrm{mM}$ with respect to nitrogen and further diluted in Hepes buffed glucose (HBG: $10 \mathrm{mM}$ Hepes, 5\% w/v glucose, $\mathrm{pH} 7.4$ ) as needed. DOPE-PEI was synthesized from PEI 1.8kDa and glutaryl-modified DOPE (NGPE) as described in [26], and kindly supplied by Professor Vladimir Torchilin's laboratory as a lyophilized 
powder. Briefly, NGPE in chloroform was activated with $\mathrm{N}$-(3-dimethylaminopropyl)-N'ethylcarbodiimide $\mathrm{HCl}$ (EDCI) and N-hydroxysuccinimide (NHS) in the presence of triethylamine at room temperature (RT) for $4 \mathrm{~h}$. PEI $1.8 \mathrm{kDa}$ was dissolved in chloroform and the activated acid solution was added drop-wise into the PEI solution while stirring and the mixture was stirred at RT overnight. The chloroform was evaporated in a rotary evaporator and freeze-dried to remove traces of chloroform. The residue was suspended in $2 \mathrm{ml}$ of deionized water $\left(\mathrm{dH}_{2} \mathrm{O}\right)$ and purified by dialysis (MWCO $2 \mathrm{kDa}$ ) against $\mathrm{dH}_{2} \mathrm{O}$ and freeze-dried. The product was dissolved in chloroform and characterized by ${ }^{1} \mathrm{H}$ NMR using a Varian $500 \mathrm{MHz}$ spectroscope. Using the standard pyrene method, the CMC of DOPE-PEI was determined to be $0.034 \mathrm{mg} / \mathrm{ml}(0.013 \mathrm{mM})$ [26]. Before use DOPE-PEI was dissolved in MQ water to a concentration $15.4 \mathrm{mM}$ with respect to nitrogen (1 $\mathrm{mg} / \mathrm{mL}$ ) and further diluted in HBG as needed. All siRNA duplexes were purchased from Eurofins MWG Operon (Germany): siRNA targeting green fluorescent protein (GFP-siRNA): 5'GGCUACGUCCAGGAGCGCACC(dTdT)-3' (sense) and siRNA targeting Luciferase (5'CUUACGCUGAGUACUUCGA(dTdT)-3' (sense). PicoGreen and Lipofectamine ${ }^{\circledR}$ RNAimax were purchased from Invitrogen (US) and Na-Heparin from porcine intestinal mucosa was purchased from Sigma-Aldrich (US). The CellTiter 96® AQueous Non-Radioactive Cell Proliferation Assay (MTS) was purchased from Promega (US).

The cell line HT1080 (human fibrosarcoma, ATCC no. CCL-121) was transfected to stably express luciferase and is referred to as $\mathrm{HT} 1080 \mathrm{pLUC}$. The cells were cultured at $37^{\circ} \mathrm{C}, 5 \% \mathrm{CO}_{2}$ in $\mathrm{RPMI}$ 1640 (Sigma-Aldrich) supplemented with 10\% fetal bovine serum (FBS, heat-inactivated, Fisher Scientific), penicillin at 100 units $/ \mathrm{mL}$ (pen), streptomycin at $100 \mathrm{mg} / \mathrm{mL}$ (strep), and Genticin (G418) at $0.8 \mathrm{mg} / \mathrm{mL}$ (all from Sigma-Aldrich). For knockdown experiments the selection antibiotic, G418, was omitted from the culture medium. 


\subsection{Preparation of polyplexes}

The N/P ratio of the present polyplexes is defined as the molar ratio of the total number of nitrogen atoms in the PEI segment of the polymer or lipid-conjugated polymer to the number of siRNA phosphates. Polyplexes with varying N/P ratios were formulated by adding a volume $(\approx 35 \mu \mathrm{L})$ from a siRNA solution in water to an equal volume of a solution of cationic polymer diluted in HBG. The final siRNA concentration was kept constant while the bPEI concentration was varied with the different N/P ratios. Each resulting formulation mixture was first mixed by pipetting up and down 10 times, then vortexed gently for $15 \mathrm{~s}$ and then incubated for $45 \mathrm{~min}$ at RT before further use. The final concentration of siRNA in all formulation mixtures was $0.039 \mu \mathrm{g} / \mathrm{uL}$.

\subsection{Size and zeta potential of polyplexes}

The hydrodynamic diameter (particle size), polydispersity and zeta potential of the polyplexes were determined using dynamic light scattering (DLS) on a ZetaPals (Brookhaven Instrument Corporation, Holtsville, NY, USA) at $25^{\circ} \mathrm{C}$ with an angle of $90^{\circ}$. Data was recorded using Brookhaven Instrument Corporation's Particle Solutions software. Before zeta potential measurements the electrode was conditioned in a $1 \mathrm{M} \mathrm{KCl}$ solution. Polyplexes were prepared as described above and diluted up to a volume of $1.75 \mathrm{~mL}$ in $\mathrm{HBG}$ and measured immediately after preparation. The particle size was determined by five runs of $30 \mathrm{~s}$ each on three separate preparations. Zeta potential determination of each sample was carried out by 10 runs with a target residual of $3.5 \times 10^{-2}$, three separate preparations per N/P ratio.

\subsection{Polyplex formation and dissociation analysis by PicoGreen exclusion assay}

The complex formation between siRNA and the cationic polymers was studied in an exclusion assay using the fluorescent intercalating dye PicoGreen. PicoGreen shows maximum fluorescence at $535 \mathrm{~nm}$ when it intercalates between the bases in double stranded RNA (and DNA) while 
showing virtually none in the absence of intercalation, and is thus a highly sensitive detector of accessible siRNA, in this case meaning uncomplexed siRNA. Polyplexes were prepared at different $\mathrm{N} / \mathrm{P}$ ratios at $\mathrm{RT}$ as described above and transferred to a dark microtiter plate and PicoGreen solution was added. The fluorescence of the polyplex dispersions $\left(\lambda_{\mathrm{ex}}=485 \mathrm{~nm}, \lambda_{\mathrm{em}}=535 \mathrm{~nm}\right)$ was measured 10 min after addition of PicoGreen on a Victor 3 plate reader (Perkin-Elmer, US) using Wallac 1420 Workstation vs 3.0 software.

To study the dissociation of the polyplexes when exposed to a competing polyanion, increasing amount of heparin was added to the polyplex dispersions after $45 \mathrm{~min}$ incubation. When the negatively charged heparin is added to the dispersions of the polyplexes, it competes with the siRNA for binding to the cationic bPEI, potentially leading to the displacement of siRNA from the polyplex. The resulting mixtures were incubated for $30 \mathrm{~min}$ at RT and measured on the Victor 3 plate reader. The relative fluorescence values and thus the percentage of accessible (= uncondensed) siRNA were determined and reported as percent fluorescence of free siRNA in the absence of vector. All results are corrected for fluorescence quenching by heparin and each experimental condition was done in triplicates.

\subsection{Polyplex formation visualization by gel electrophoresis}

The polyplex formation between siRNA and the polycations was further evaluated using agarose gel electrophoresis; exploiting the fact that naked siRNA readily migrates in an agarose gel while polyplexes are retained in the wells. Each preparation of polyplex with a desired N/P ratio was loaded onto a $2 \%(\mathrm{w} / \mathrm{v})$ agarose gel containing ethidium bromide (Sigma-Aldrich) in Tris-Acetate EDTA buffer. The amount of siRNA loaded into each well was 69 pmol in a total volume of $12 \mu \mathrm{L}$ including loading buffer ( $1 \mathrm{mM}$ cresol red in $0.6 \mathrm{M}$ sucrose). The electrophoresis was performed at 
$50 \mathrm{~V}$ for $35 \mathrm{~min}$ and siRNA bands were visualized using a BioSpectrum ${ }^{\circledR}$ Imaging System with the VisionWorksLS software package (excitation at $480 \mathrm{~nm}$, emission filter at 570-640 nm.)

\subsection{Knockdown of luciferase}

HT1080 pLuc cells, which stably expressed luciferase, were seeded in RPMI 1640 medium with $10 \% \mathrm{FBS}, 5 \% \mathrm{pen} / \mathrm{strep}$ (complete medium) in 24 -well plates $24 \mathrm{~h}$ prior to transfection $(50,000$ cells per well). The cells were washed with PBS, polyplexes formulated as described above were further diluted in RPMI 1640 medium with 5\% pen/strep (serum free medium) and added to the cells resulting in a final concentration of $120 \mathrm{nM}$ siRNA per well. The cells were incubated with polyplexes for $6 \mathrm{~h}$, transfection medium was removed, and the cells were washed with PBS and incubated for an additional $22 \mathrm{~h}$ in complete medium. The cells were then washed once with PBS and lysed using $125 \mu \mathrm{L}$ Reporter Lysis Buffer (Promega, US). Luciferase activity was measured using a luciferase assay [33] with D-luciferin (Caliper Life Sciences, US). Each sample was measured for $10 \mathrm{~s}$ on a luminometer (Lumat LB9507 with Lumat firmware, Berthold, Germany). The total lysate protein concentration was determined using the BCA kit (Pierce, US) and the gene expression was normalized to the total protein concentration in the cell lysate and described as luciferase activity (relative light units) per $\mu \mathrm{g}$ protein. All knockdown assays comprised, as a positive control, Lipofectamine ${ }^{\circledR}$ RNAimax using 30 pmol of siRNA. In addition, all assays comprised a non-sense control using siRNA directed against GFP as well as anti-luciferase siRNA administrated unassociated to vector. The non-sense control was prepared using N/P16 for DOPEPEI and N/P3 for bPEI 25kDa and PEI 1.8kDa. Each experimental condition was done in triplicates.

For experiments to examine the importance of the free fraction, the extra vector material was diluted in serum free medium and added to cell cultures which had already been incubated for $2 \mathrm{~h}$ with polyplexes formulated for full condensation of the siRNA. Specifically, HT1080pLuc cells 
were incubated with polyplexes formed at the N/P ratio of full condensation for $2 \mathrm{~h}$ (N/P2 for bPEI $25 \mathrm{kDa}$ and N/5 for DOPE-PEI). Then, the free fraction was added to the incubations, resulting in a total N/P ratio of 3 for bPEI $25 \mathrm{kDa}$ and 16 for DOPE-PEI. The cultures were then incubated with the mix of fully condensed polyplexes and separately added free fraction for 1, 2 or $4 \mathrm{~h}$ resulting in a total incubation time of 3,4 or $6 \mathrm{~h}$. After end of incubation with the mix of polyplexes and separately added free fraction, the cells were washed in PBS, fresh complete medium was added and the cells were incubated to a total of $28 \mathrm{~h}$ until lysis and analysis of gene knockdown. Control cells were incubated in parallel with fully condensed polyplexes or optimally formulated polyplexes. Each experimental condition was done in triplicates.

\subsection{Radiolabeling of siRNA}

Luc siRNA (MWG Eurofins Operon, Germany) was labeled with radioactive ${ }^{33} \mathrm{P}$ using the kit for phosphorylation of DNA with T4 Polynucleotide Kinase (Fisher Scientific, US). The T4 Polynucleotide Kinase was used to catalyze the transfer of ${ }^{33} \mathrm{P}$ from $\left[\gamma-{ }^{33} \mathrm{P}\right]$-ATP (Perkin Elmer, US) to the free hydroxyl end (5') of luciferase siRNA. The reaction was stopped by addition of EDTA and the product was purified using the QIAquick nucleotide removal kit (Qiagen, Germany). Care was taken not to damage any secondary structure of the siRNA, accordingly the reaction mixture was never heated above $40^{\circ} \mathrm{C}$.

\subsection{In vitro cellular uptake}

For experiments with parallel determination of uptake and knockdown, the siRNA was spiked with

${ }^{33} \mathrm{P}$ labeled siRNA. Knockdown assays were performed as described above and the experiments were terminated by removal of the medium and the cells were washed with PBS containing 0.11 $\mathrm{mg} / \mathrm{mL}$ heparin in order to remove polyplexes bound to the plasma membranes and once with PBS. The cells were then lysed as described above, luciferase and BCA assays were performed and $65 \mu \mathrm{L}$ 
lysate per population was mixed with $5 \mathrm{~mL}$ scintillation liquid (UltimaGold, Perkin Elmer, US) and radioactivity was measured as counts per minute using a Packard Tri-carb Liquid Scintillation Analyzer 1900CA (Packard Biosciences, US) equipped with Packard firmware. Each experimental condition was done in triplicates.

\subsection{Cytotoxicity of polymers and polyplexes}

The cytotoxicity of free vector polymers and the corresponding polyplex dispersions was evaluated on HT1080 pLuc cells using the MTS assay (CellTiter 96® Aqueous Non-Radioactive Cell Proliferation assay, Promega, USA). Cells were seeded in a 96-well plate at an initial density of 10,000 cells per well in complete medium. After $24 \mathrm{~h}$, free vector polymers or polyplexes were added to the cells at varying concentrations in serum free medium. The cells were incubated at $37^{\circ} \mathrm{C}, 5 \% \mathrm{CO}_{2}$ for $24 \mathrm{~h}$. The MTS working solution was then added to each well $(20 \mu \mathrm{L})$. The cells were further incubated for $1 \mathrm{~h}$ at $37^{\circ} \mathrm{C}$ and absorbance was measured $(490 \mathrm{~nm}$, Victor 3 plate reader with Wallac 1420 Workstation vs 3.0 software). Cytotoxicity was reported as percent cell viability using untreated cells as $100 \%$ (triplicate measurements).

\subsection{Ratiometric $\mathrm{pH}$ measurements in the lysosomal compartment}

Measurements of lysosomal $\mathrm{pH}$ were performed with a triple-labelled fluorescent nanosensor as described in our published protocol and review [34,35]. Briefly, HT1080 cells were plated in Ibidi 8-well $\mu$-slides $(27,000$ cells/well in $300 \mu \mathrm{L} /$ well $)$ in complete medium and incubated overnight. On day 2 , medium was changed to complete medium with $25 \mu \mathrm{g} / \mathrm{mL}$ nanosensor. On day 3 , cells were carefully washed once in PBS-Heparin $(0.111 \mu \mathrm{g} / \mathrm{mL}$ heparin in PBS $)$ and once in PBS in order to remove un-internalized nanosensor. Then vector polymers were added in the following concentrations: $0.73 \mu \mathrm{g} / \mathrm{mL}$ (bPEI $1.8 \mathrm{kDa}$, bPEI $25 \mathrm{kDa}$ ) and $5.7 \mu \mathrm{g} / \mathrm{mL}$ (DOPE-PEI) in imaging medium (full growth medium without phenol red). These concentrations are $10 \%$ higher than for 
any in vitro cell assay with polyplexes, but below a level where significant cytotoxicity is observed. Confocal images were recorded at 0,2 and $6 \mathrm{~h}$, where after the cells were washed once in PBSHeparin and once in PBS and kept in imaging medium. Additional images were then acquired 10 and $24 \mathrm{~h}$ after addition of bPEI. Images were captured by a Leica TCS SP5 confocal microscope with a $63 \mathrm{x}$ water-immersion objective. The microscope is equipped with an incubator box and $\mathrm{CO}_{2}$ supply for optimal growth conditions during imaging. Images were acquired with fixed settings for all samples and the corresponding calibration curve. We used Leica Application Suite for Advanced Fluorescence for data recording and in-house developed software for ratiometric $\mathrm{pH}$ calculations. Two-color images were obtained by sequential line scanning with the following excitation/emission wavelengths: $488 / 493-560 \mathrm{~nm}$ and $561 / 566-680 \mathrm{~nm}$. At each time point, before imaging the PEI treated cells, a control experiment was performed in order to optimize the microscope settings. One well containing cells unexposed to bPEI or PEI-derivative, but with nanosensor, was treated with $200 \mathrm{nM}$ Bafilomycin A1 for $40 \mathrm{~min}$ and used to optimize microscope settings. This treatment increases the $\mathrm{pH}$ of the lysosomes and adjusting the imaging settings to achieve maximum signal for this sample, ensures optimal use of the dynamic range of the nanosensor. Ten images were acquired of this sample and of an untreated sample (no PEIs or Bafilomycon A1, but with nanosensor) where after 15 images were acquired of each of the three PEI samples (per time-point). A calibration curve was prepared by diluting the nanosensor in buffers $(20 \mathrm{mM}$ phosphate $/ 20 \mathrm{mM}$ citrate/20 mM malate/100 $\mathrm{mM} \mathrm{NaCl}$ ) from $\mathrm{pH}$ 2.8-7.5 with a final nanosensor concentration of 10 $\mathrm{mg} / \mathrm{mL}$. Each solution $(2.5 \mu \mathrm{L})$ was transferred to a diagnostic microscope slide, sealed with a cover glass and imaged. The calibration curve was fitted to the following equation for a triplelabeled nanosensor:

$$
R=\frac{R_{1}}{10^{p K a_{1}-p H}+1}+\frac{R_{2}}{10^{p K a_{2}-p H}+1}+R_{0}
$$


where $R$ is the ratio of emission intensities excited at 488 and $561 \mathrm{~nm}, \mathrm{R}_{0}=\mathrm{R}_{\min }$ (the ratio for the fully protonated form), $\left(\mathrm{R}_{0}+\mathrm{R}_{1}+\mathrm{R}_{2}\right)=\mathrm{R}_{\max }$ (the ratio of the fully deprotonated form), and $\mathrm{pKa} \mathrm{a}_{1}$ and $\mathrm{pKa}_{2}$ are the specific $\mathrm{pKa}$ values of the two $\mathrm{pH}$-sensitive fluorophores in the nanoparticle. Image analysis was performed as described previously using a pixel based method [34,36]. Briefly, image processing was used in order to determine which pixels are actual signal from the nanosensor and the included pixels were then converted to $\mathrm{pH}$ via the calibration curve. $\mathrm{pH}$ histograms are presented as mean \pm SEM. $\mathrm{pH}$ images were generated by coloring single pixels according to a linear $\mathrm{pH}$ color scale. Additionally, phase contrast images were acquired at 2, 6, 10 and $24 \mathrm{~h}$ time-points to confirm cell viability and illustrate non-toxic footprint of nanosensor.

\subsection{Statistical Analysis}

Statistical analysis was performed using Prism 6 (Graphpad Software, US). Each experiment was performed at least three times with triplicate measurements. Unless otherwise stated, data points represent mean of triplicate $\pm \mathrm{SD}$. Trend lines are 4 or 5 parameter fits. Statistical analysis used $\mathrm{t}$ test with significance levels being symbolized by $*$ if $\mathrm{p}<0.005$ and $* *$ if $\mathrm{p}<0.001$.

\section{Results}

\subsection{Cytotoxicity of vector polymers and polyplexes}

To establish the toxicity profiles of bPEI 25kDa, bPEI $1.8 \mathrm{kDa}$ and DOPE-PEI, we used a cell viability assay (Promega's MTS kit) to investigate the free vector polymers (Fig. 1) and the siRNA containing polyplexes (Fig. 2).

Fig. 1 shows that all three polymers are associated with some cytotoxicity with bPEI $25 \mathrm{kDa}$ being the most cytotoxic. Importantly, formulation of the vectors into polyplexes greatly diminishes this 
inherent cytotoxicity, most pronounced for bPEI 25kDa and DOPE-PEI (Fig. 2). The selected N/P ratios are those involved in subsequent in vitro knockdown studies as described in detail later.

\subsection{Lysosomal $\mathrm{pH}$}

The proton-sponge effect remains the dominant hypothesis used to explain the ability of PEI to promote high transfection levels, and this effect has been hypothesized to result in increased $\mathrm{pH}$ levels in the lysosomes. We therefore measured the lysosomal $\mathrm{pH}$ in cells incubated with PEI 1.8kDa, DOPE-PEI, and bPEI 25kDa using a triple-labeled ratiometric nanosensor that we have developed [34,36,37] to compare the lipid conjugated PEI with conventional PEIs. This nanosensor with the two $\mathrm{pH}$-sensitive fluorophores Oregon Green and fluorescein and the $\mathrm{pH}$-insensitive fluorophore rhodamine $\mathrm{B}$ is superior to earlier reported $\mathrm{pH}$ sensors with respect to the sensitivity range (pH 3.2-7.0), especially when obtaining measurements in the lysosomes [36].

For the lysosomal $\mathrm{pH}$ measurements, cells were treated for 24 hours with the nanosensor and then exposed to the different PEIs and imaged by confocal microscopy at different time points. Fig. 3A shows that the $\mathrm{pH}$ distributions obtained from cells treated with bPEI 25kDa or DOPE-PEI do not differ from those obtained from the untreated control cells. As a positive control, we treated cells with the Vacuolar-type H+-ATPase (V-ATPase) inhibitor Bafilomycin A1, which is known to inhibit the acidification of the lysosomes. This sample displayed a significant increase in $\mathrm{pH}$, up to around $\mathrm{pH}$ 6.0, which is in agreement with previously published results [38,39], confirming that the nanosensor is capable of measuring an increase in $\mathrm{pH}$. As Bafilomycin $\mathrm{A} 1$ is an inhibitor of the $\mathrm{V}$ ATPase it does not block the action of the pump completely, which is why we do not observe $\mathrm{pH}$ values closer to the physiologically neutral level of $\mathrm{pH}$ 7.4. The lysosomal $\mathrm{pH}$ is visually presented in Fig. 3B which shows images from the $6 \mathrm{~h}$ time-point. A lack of change in color between the Control and DOPE-PEI treated cells indicates no change in lysosomal $\mathrm{pH}$. Finally, the $\mathrm{pH}$ as a 
function of time is presented in Fig. 3C for the Control and DOPE-PEI treated samples under exactly the same conditions over a period of $24 \mathrm{~h}$, and no change in $\mathrm{pH}$ is observed over time. It is important to keep in mind that the nanosensor resides in the lysosomes, and that the reported $\mathrm{pH}$ measurements exclusively regard lysosomal $\mathrm{pH}$ irrespective of when the polyplexes may reach this compartment. Conclusively, we do not find that lipid conjugated PEI changes the $\mathrm{pH}$ in the lysosomal compartment, which is thereby similar to our previous study evaluating the proton sponge effect of conventional PEI [35].

Phase contrast images (Supplementary Fig. 1) indicate that the combined exposure to nanosensor and bPEI / bPEI-derivative has a minimal impact on cell viability at the concentrations used. Furthermore, we have previously established that the nanosensor does not affect cell viability $[34,35]$.

\subsection{Size and zeta potential of the polyplexes}

Size and charge of polyplexes greatly influences the efficiency of cellular uptake. Therefore, the complex formation of bPEI $1.8 \mathrm{kDa}$, bPEI $25 \mathrm{kDa}$ and DOPE-PEI with siRNA was characterized. In HBG, all three vectors are able to condense the siRNA cargo into small particles with DOPE-PEI consistently forming the smallest particles (Fig. 4A). The zeta potentials of the polyplexes are positive at $\mathrm{N} / \mathrm{P} \geq 3$ for $\mathrm{bPEI} 1.8 \mathrm{kDa}$ and $\mathrm{bPEI} 25 \mathrm{kDa}$, or at $\mathrm{N} / \mathrm{P} \geq 6$ for DOPE-PEI. The higher N/P ratio for transition from negative to positive zeta potential for DOPE-PEI reflects the altered condensation properties of this vector due to the lipid conjugation.

\subsection{Condensation and decondensation properties of the polyplexes}

The balance between cargo condensation extracellularly and dissociation intracellularly is crucial for efficient transfection and previous reports have indicated full condensation of siRNA cargo by bPEI 1.8kDa at N/P2 and DOPE-PEI at N/P3 [29]. We examined the ability of all three polymers to 
condense siRNA using the PicoGreen exclusion assay as well as gel-shift assays. The differences in condensation behavior of the three polymers are depicted in Fig. 5, which shows that bPEI 1.8kDa and bPEI $25 \mathrm{kDa}$ reaches full and similar condensation of the siRNA at N/P2 in agreement with literature [29]. In contrast, DOPE-PEI does not reach full condensation until N/P5. These results are supported by the gel-shift assays (Supplementary Fig. 2) as well as the zeta potential measurements (Fig. 4B), which all indicate altered lipid-siRNA interaction due to the lipid conjugation.

Anionic competition for binding to the vector polymers is one way to assess the strength of the siRNA-vector association, and we therefore monitored the heparin-induced release of siRNA or decondensation of the polyplexes through the fluorescence intensity of PicoGreen (Fig. 6). Surprisingly, bPEI $25 \mathrm{kDa}$ polyplexes were the most vulnerable to competition from heparin as they decondense to a level of $40 \%$ PicoGreen accessibility (percentage relative to free siRNA). In contrast, bPEI $1.8 \mathrm{kDa}$ and DOPE-PEI reaches plateaus of PicoGreen accessibility of only $5 \%$ and $10 \%$, respectively.

\subsection{In vitro knockdown studies}

To systematically analyze and compare the performance of bPEI 25kDa, bPEI $1.8 \mathrm{kDa}$ and DOPEPEI as delivery agents of siRNA, we established the optimum balance between knockdown and induction of cytotoxicity in an HT1080pLUC cell line. bPEI $1.8 \mathrm{kDa}$ was unable to suppress expression of luciferase, while bPEI $25 \mathrm{kDa}$ showed efficient knockdown, reaching a plateau of maximum knockdown at N/P3. Lipid conjugation of bPEI $1.8 \mathrm{kDa}$ transformed the polycation into an efficient transfection agent reaching a plateau of maximum knockdown at N/P16 (Fig. 7). Above these N/P ratios the cytotoxic impact of the polyplexes gradually became apparent. We therefore conclude that bPEI $25 \mathrm{kDa}$ at N/P3 and DOPE-PEI at N/P16 strikes an optimal balance between knockdown and absence of cytotoxicity and regarded these formulations as optimal. For referencing 
with Fig. 1 and 2, these N/P ratios translate to $0.67 \mu \mathrm{g} / \mathrm{mL}$ (bPEI $1.8 \mathrm{kDa}$ and $25 \mathrm{kDa}$ ) and 5.2 $\mu \mathrm{g} / \mathrm{mL}$ (DOPE-PEI) in our in vitro assays, where none of the transfection systems show toxicity.

The results of Fig. 3-7 demonstrate that the full transfection potential of each vector is realized at higher N/P ratios than where full siRNA condensation is observed. However, compared to similar experiments with DNA using bPEI $25 \mathrm{kDa}[30]$, it is notable that the N/P ratio necessary to achieve maximum knockdown is much lower with siRNA than DNA cargo (N/P3 vs N/P8, respectively).

As efficient knockdown required use of vector material in excess of what was required for full siRNA condensation, we wanted to investigate the role and importance of this vector fraction (which we have termed the "free fraction") and how the lipid conjugation affected the behavior of the free fraction compared to the conventional bPEI 25kDa (Fig. 8). This was assessed as the ability of the free fraction to improve the knockdown capability of polyplexes formed at the N/P ratio for full condensation. We therefore incubated our reporter cell line with fully condensed polyplexes for two hours, added free vector, incubated further, washed to remove uninternalized material, incubated to a total of $28 \mathrm{~h}$ and analyzed knockdown.

DOPE-PEI and bPEI $25 \mathrm{kDa}$ differ in the degree to which delayed addition of the free fraction results in as large a knockdown as optimal N/P ratios. For bPEI $25 \mathrm{kDa}$, delayed addition of the free fraction results in a knockdown, which is statistically identical to the populations that were incubated with polyplexes formulated with the optimal N/P ratio (Fig. 8A-C). For DOPE-PEI, delayed addition of the free fraction increases the knockdown but not to the level of optimally formulated particles (N/P16) (Fig. 8D-F), indicating that lipid conjugation also influences the interaction of the vectors with the cells. 


\subsection{Uptake}

To elucidate how the N/P ratio influenced the uptake and concomitant knockdown, and to see if polyplexes of DOPE-PEI behaved differently than polyplexes of conventional bPEIs, we performed in vitro knockdown assays using radioactively labeled Luciferase siRNA (Fig. 9).

The knockdown profiles in Fig. 9 confirm the trends from Fig. 8, i.e. a large knockdown by RNAimax (85\%), bPEI 25kDa at N/P3 (77\%) and DOPE-PEI at N/P16 (86\%), a small knockdown by bPEI $25 \mathrm{kDa}$ at N/P2 (34\%) and complete absence of knockdown from bPEI 1.8kDa at N/P2 and 3, DOPE-PEI at N/P5 and uncomplexed siRNA. These observations correlate well with the uptake data, to the extent that bPEI $25 \mathrm{kDa}$ at N/P3 and DOPE-PEI at N/P16 show relatively high siRNA uptake levels compared with very low uptake levels for bPEI $1.8 \mathrm{kDa}$ at $\mathrm{N} / \mathrm{P} 2$ and 3 and uncomplexed siRNA. However, considerable complexity is added by the following observations: 1) bPEI $25 \mathrm{kDa}$ at N/P2 consistently induces a significantly higher siRNA uptake than bPEI 25kDa at $\mathrm{N} / \mathrm{P} 3(\mathrm{p}<0.001)$, but bPEI $25 \mathrm{kDa}$ at N/P2 induces only a small knockdown, 2) DOPE-PEI at N/P5 is taken up to a considerable extent but induces no knockdown, and 3) RNAimax is never internalized to more than $2 \%$ of the available siRNA but remains as efficacious as DOPE-PEI at N/P16 and bPEI $25 \mathrm{kDa}$ at N/P3.

\section{Discussion}

Safe and efficient delivery of siRNA to the cytoplasm of target cells is a prerequisite for knockdown of a target gene. To enable rational and focused design of siRNA delivery systems, detailed knowledge of the interaction between the vector polymers and the siRNA as well as between the polyplexes and the cells is necessary. PEI has been extensively characterized for DNA delivery $[30-32,40]$. For instance, it has been shown that high efficiency requires N/P ratios $>8[30,40]$, 
while full condensation of the DNA is reached at N/P3-4 [30,31,41]. This indicates that a fraction of the vector has a role unrelated to condensation of DNA, and this fraction has been speculated to be free in solution or at least only weakly associated to the nucleic acid-containing polyplex. siRNA delivery by PEI has been much less studied, but as size and electrostatic density of the cargo as well as intracellular compartment and molecular machinery of action differs for siRNA in comparison to DNA, it is not possible to directly extrapolate mechanistic results from DNA to the delivery of siRNA [42]. Therefore, the mechanistics of siRNA delivery using bPEI and the lipid conjugate of bPEI has been investigated in this study.

At similar polycation concentrations, fully condensed polyplexes based on DOPE-PEI display lower cytotoxicity than fully condensed polyplexes with bPEI $1.8 \mathrm{kDa}$ and bPEI $25 \mathrm{kDa}$ (Fig. 2, filled symbols). Further, at our assay concentrations, lipid conjugation of bPEI $1.8 \mathrm{kDa}$ has not increased the inherent cytotoxicity of bPEI 1.8kDa (Fig. 1) in spite of DOPE having high membrane affinity and fusogenic capability [43,44]. However, comparing polyplexes of bPEI $25 \mathrm{kDa}$ and DOPE-PEI at the optimal N/P ratios (Fig. 2A and B) show that there is no beneficial effect of DOPE-conjugation in terms of a reduction of cytotoxicity. While DOPE-PEI based polyplexes are less cytotoxic than polyplexes based on bPEI $25 \mathrm{kDa}$ at corresponding vector concentrations, this benefit is eliminated by the larger amounts of DOPE-PEI necessary to achieve the same knockdown effect as with bPEI $25 \mathrm{kDa}$. On the other hand, DOPE-PEI may have advantageous formulation properties; the hydrocarbon moiety of DOPE-PEI could enable formulation into liposomes or establish otherwise impossible lipid-lipid interactions as described by Sawant et al. with DNA cargo $[26]$.

One aspect where DNA and siRNA polyplexes based on bPEI differ is the stability against polyanions such as heparin; siRNA polyplexes with bPEI $25 \mathrm{kDa}$ are much more sensitive to 
heparin mediated decondensation than siRNA polyplexes with bPEI 1.8kDa and DOPE-PEI. This was surprising since we have observed the opposite for DNA, where a heparin:DNA ratio of 10 results in $15 \%$ decondensation for bPEI $25 \mathrm{kDa}$-polyplexes and $70 \%$ for bPEI $1.8 \mathrm{kDa}$-polyplexes (unpublished results). This difference between DNA and siRNA is probably due to the smaller size of the siRNA compared to the DNA plasmids, which allow a more efficient packing of the siRNA, and the effect is probably assisted by the higher conformational rigidity of bPEI $25 \mathrm{kDa}$ compared to bPEI $1.8 \mathrm{kDa}$ and DOPE-PEI [45]. Thus, for siRNA, bPEI $1.8 \mathrm{kDa}$ and DOPE-PEI appear to form stronger interactions with the siRNA than bPEI $25 \mathrm{kDa}$.

The size measurements in HBG (Fig. 4A) demonstrate that all three polycations are able to condense siRNA and form particles that are smaller than $200 \mathrm{~nm}$, which is believed to be the upper size limit of clathrin-mediated endocytosis [46]. Furthermore, the zeta potential measurements, PicoGreen exclusion and gel shift assays (Fig. 4B, Fig. 5 and Supplementary Fig. 2, respectively) confirm that at the N/P ratio that gives optimal transfection efficiency (N/P3 for bPEI 25kDa and N/P16 for DOPE-PEI), vector in excess of the requirements for maximum achievable siRNA condensation is present. In addition, the cytotoxicity results (Fig. 1 and 2) show that the free vector polymers are much more cytotoxic than polyplexes containing an equivalent amount of polymer, and that the toxicity increases markedly when going from N/P2 to N/P3 for bPEI 25kDa or from N/P5 to N/P16 for DOPE-PEI. Combined, these data support that at the optimal N/P ratios two vector fractions exist, one that is tightly bound in the core polyplex and one which is less tightly associated (a free fraction), each fraction with potentially different functions in the transfection process.

The results demonstrate key differences between siRNA and DNA condensation as well as differences between the regular bPEIs and DOPE-PEI. Firstly, bPEI 25kDa condenses siRNA better 
than DNA [30,32], probably due to the smaller size of the siRNA duplexes compared to the DNA plasmids. Secondly, much higher N/P ratios are required for full siRNA condensation by DOPEPEI than the conventional bPEIs. One possible explanation for this could be that DOPE-PEI is unable to pair as many of its charged nitrogens as regular bPEI due to steric hindrance.

The observation that a free fraction of vector is necessary for efficient knockdown, prompted us to examine the role of the free vector in the form of experiments with simultaneous determination of knockdown and siRNA uptake and experiments with delayed addition of the free fraction.

For bPEI $25 \mathrm{kDa}$, the delay experiments show that the free fraction is not associated to the siRNAcontaining polyplexes, since separate addition of excess vector material to fully condensed siRNAcontaining polyplexes (N/P2) results in knockdown statistically identical to the knockdown achieved with optimally formulated polyplexes (Fig. 8A-C). DOPE-PEI does not fully share the behavior of bPEI $25 \mathrm{kDa}$. Even though delayed addition of the free fraction does have a significant impact on the knockdown, it does not reach the level of knockdown of optimally formulated polyplexes (N/P16) (Fig. 8D-F). This probably reflects the altered cell-polymer interactions due to the ability to form lipid-lipid interactions.

The siRNA uptake data (Fig. 9) demonstrate that the polyplexes based on bPEI 25kDa N/P3 and DOPE-PEI N/P16 are internalized to approximately the same extent, corresponding well to the induction of comparable knockdown in our HT1080 cell line. Conversely, polyplexes based on bPEI $1.8 \mathrm{kDa}$ are unable to induce knockdown and show only limited uptake, demonstrating that lipid conjugation of low Mw bPEI with the intent to increase membrane interaction is a constructive strategy [26,28]. Surprisingly, bPEI $25 \mathrm{kDa}$ consistently facilitates higher siRNA uptake at N/P2 than N/P3 $(\mathrm{P}<0.001)$ although large knockdown requires the free fraction. This shows that the free fraction exerts its influence separately from the siRNA-containing core polyplexes, and the higher 
uptake by N/P2 than N/P3 bPEI $25 \mathrm{kDa}$ polyplexes suggests that the free fraction plays a role unrelated to uptake. This could be by facilitating endosomal escape or by facilitating alternate routes of polyplex uptake such as the caveolar pathway as suggested by Pack et al. [19] or direct membrane fusion as proposed for lipoplex uptake [47].

It is widely reported that bPEI $1.8 \mathrm{kDa}$ is inefficient for DNA delivery while bPEI $25 \mathrm{kDa}$ is highly efficient [30], and we confirm this trend for siRNA. Many published reports on DNA transfection have compared polyplexes of these two polymers prepared at the same N/P ratio, which should provide the two polymers with equal proton-sponge capability. Our data shows that it is the internalization step that causes the efficiency gap between bPEI $1.8 \mathrm{kDa}$ and bPEI $25 \mathrm{kDa}$, not necessarily the ability to induce endosomal escape. This hypothesis is in agreement with the work of Navarro and coworkers [48], who reported that the use of high N/P ratios and chloroquine did not enable bPEI $1.8 \mathrm{kDa}$ to induce knockdown. It is likely that it is the interaction with the plasma membrane that differs, although the specific mechanism for this membrane interaction remains to be elucidated. One structural advantage of bPEI $25 \mathrm{kDa}$ over bPEI $1.8 \mathrm{kDa}$ could be the ability to more efficiently cross-bind multiple anionic membrane proteins on the target cell plasma membrane, potentially influencing the uptake process through this interaction. Indeed, crossbinding of cell surface receptors has been shown to be able to induce clathrin-mediated endocytosis through signaling $[49,50]$ and it would be compatible with the uptake improvement observed for lipid conjugated bPEI $1.8 \mathrm{kDa}$, since lipid conjugation may increase membrane interactions and therefore potentially improve bPEI $1.8 \mathrm{kDa}$ 's ability to induce endocytosis. Alternatively, it is possible that insertion of the lipid portion of DOPE-PEI into the plasma membrane induces membrane invaginations, which may facilitate endocytosis similar to observations by Cheng and coworkers [51]. 
The proton sponge effect has been hypothesized to cause an increase in the $\mathrm{pH}$ and osmotic swelling of PEI-containing lysosomes resulting in loss of membrane integrity and leakage of the nucleic acid cargo into the cytosol $[9,18]$. We have previously shown that no change in lysosomal $\mathrm{pH}$ can be observed for bPEIs $25 \mathrm{kDa}$ [37]. However, DOPE-PEI show different properties and behavior, and as the free fraction appear to play a role after polyplex uptake, we investigated if the lipid conjugation would change the ability of DOPE-PEI to influence lysosomal $\mathrm{pH}$. We measured the $\mathrm{pH}$ in the lysosomes of cells exposed to the three vectors, but were unable to measure any perturbation of the $\mathrm{pH}$ by any of the PEIs compared to the untreated control cells. The positive control cells treated with Bafilomycin A1 displayed the expected increase in $\mathrm{pH}[38,39]$. However, even though we do not observe an increase in $\mathrm{pH}$, the PEI polymer could still cause influx of first $\mathrm{H}^{+}$, then $\mathrm{Cl}^{-}$and water but with the $\mathrm{V}$-ATPase being able to compensate and maintain the $\mathrm{pH}$ in the lysosomes. Osmotic swelling may then cause transient leakage events resulting in release of siRNA into the cytosol. The end result would be endosomal escape assisted by the proton sponge effect but without a concomitant drop in $\mathrm{pH}$.

Finally, the efficiency of induced knockdown versus siRNA uptake is much lower for all the tested PEI vectors compared to the commercial control, RNAimax. The latter is noticeably more efficient than both bPEI $25 \mathrm{kDa}$ and DOPE-PEI with an uptake percentage that never exceeds $2 \%$ (of the siRNA) while inducing a knockdown comparable to bPEI $25 \mathrm{kDa}$ and DOPE-PEI. This high efficiency is attractive, as less interaction with both siRNA and vector polymers potentially lower the cytotoxicity. 


\section{Conclusions}

Our experiments demonstrate the complexity of the cell-polyplex interactions. The importance of the free fraction for bPEI $25 \mathrm{kDa}$ and DOPE-PEI is evident - in its absence, the vectors are substantially less efficient. The considerable uptake of polyplexes of bPEI $25 \mathrm{kDa}$ at N/P2 and DOPE-PEI at N/P5 without concomitant knockdown indicates that the most important role of the free fraction is unrelated to polyplex uptake. Regardless of the specific role of the free fraction, future development of delivery systems for siRNA should consider the presence and potential role

of a free vector fraction and how this can be controlled for in vivo delivery purposes. Lipid conjugation of $\mathrm{bPEI} 1.8 \mathrm{kDa}$ does not in itself provide the solution to the high cytotoxicity of bPEI $25 \mathrm{kDa}$ or the low efficiency of bPEI $1.8 \mathrm{kDa}$. However, DOPE-PEIs ability to form lipid-based interactions may enable it or a similar compound to be formulated into e.g. liposomes that can have in vivo transfection potential.

\section{Disclosure}

There are no conflicts of interest.

\section{Acknowledgments}

Financial support from the Danish Council for Strategic Research and the Technical University of Denmark is gratefully acknowledged for funding. 


\section{Appendix A. Supplementary data}

Supplementary data associated with this article can be found, in the online version, at http://... 


\section{References}

[1] R.C.C. Ryther, A.S. Flynt, J.A. Phillips, J.G. Patton, siRNA therapeutics: big potential from small RNAs, Gene Ther. 12 (2005) 5-11.

[2] K.A. Whitehead, R. Langer, D.G. Anderson, Knocking down barriers: advances in siRNA delivery, Nat. Rev. Drug Discov. 8 (2009) 129-38.

[3] P.D. Zamore, T. Tuschl, P.A. Sharp, D.P. Bartel, RNAi: double-stranded RNA directs the ATP-dependent cleavage of mRNA at 21 to 23 nucleotide intervals, Cell. 101 (2000) 25-33.

[4] S. Elbashir, W. Lendeckel, T. Tuschl, RNA interference is mediated by 21-and 22-nucleotide RNAs, Genes Dev. (2001) 188-200.

[5] M.E. Davis, J.E. Zuckerman, C.H.J. Choi, D. Seligson, A. Tolcher, C.A. Alabi, Y. Yen, J.D. Heidel, A. Ribas, Evidence of RNAi in humans from systemically administered siRNA via targeted nanoparticles, Nature. 464 (2010) 1067-70.

[6] C.E. Thomas, A. Ehrhardt, M.A. Kay, Progress and problems with the use of viral vectors for gene therapy, Nat. Rev. Genet. 4 (2003) 346-58.

[7] D.W. Pack, A.S. Hoffman, S. Pun, P.S. Stayton, Design and development of polymers for gene delivery, Nat. Rev. Drug Discov. 4 (2005) 581-93.

[8] M.A. Mintzer, E.E. Simanek, Nonviral vectors for gene delivery, Chem. Rev. 109 (2009) 259-302.

[9] O. Boussif, F. Lezoualc'h, M.A. Zanta, M.D. Mergny, D. Scherman, B. Demeneix, J.P. Behr, A versatile vector for gene and oligonucleotide transfer into cells in culture and in vivo: polyethylenimine, Proc. Natl. Acad. Sci. U. S. A. 92 (1995) 7297-301.

[10] U. Lungwitz, M. Breunig, T. Blunk, A. Göpferich, Polyethylenimine-based non-viral gene delivery systems, Eur. J. Pharm. Biopharm. 60 (2005) 247-66.

[11] M. Neu, D. Fischer, T. Kissel, Recent advances in rational gene transfer vector design based on poly(ethylene imine) and its derivatives, J. Gene Med. 7 (2005) 992-1009.

[12] L. Parhamifar, A.K. Larsen, A.C. Hunter, T.L. Andresen, S.M. Moghimi, Polycation 
cytotoxicity: a delicate matter for nucleic acid therapy_-focus on polyethylenimine, Soft Matter. 6 (2010) 4001.

[13] W.T. Godbey, K.K. Wu, A.G. Mikos, Poly(ethylenimine) and its role in gene delivery, J. Control. Release. 60 (1999) 149-60.

[14] B. Urban-Klein, S. Werth, S. Abuharbeid, F. Czubayko, A. Aigner, RNAi-mediated genetargeting through systemic application of polyethylenimine (PEI)-complexed siRNA in vivo, Gene Ther. 12 (2005) 461-6.

[15] J.-C. Bologna, G. Dorn, F. Natt, J. Weiler, Linear polyethylenimine as a tool for comparative studies of antisense and short double-stranded RNA oligonucleotides, Nucleosides. Nucleotides Nucleic Acids. 22 (2003) 1729-31.

[16] W.T. Godbey, K.K. Wu, A.G. Mikos, Tracking the intracellular path of poly(ethylenimine)/DNA complexes for gene delivery, Proc. Natl. Acad. Sci. U. S. A. 96 (1999) 5177-81.

[17] D. Hoekstra, J. Rejman, L. Wasungu, F. Shi, I. Zuhorn, Gene delivery by cationic lipids: in and out of an endosome, Biochem. Soc. Trans. 35 (2007) 68-71.

[18] J.P. Behr, The proton sponge: a trick to enter cells the viruses did not exploit, Chim. Int. J. Chem. 2 (1997) 34-36.

[19] N.P. Gabrielson, D.W. Pack, Efficient polyethylenimine-mediated gene delivery proceeds via a caveolar pathway in HeLa cells, J. Control. Release. 136 (2009) 54-61.

[20] K. Sandvig, S. Pust, T. Skotland, B. van Deurs, Clathrin-independent endocytosis: mechanisms and function, Curr. Opin. Cell Biol. 23 (2011) 413-20.

[21] K. Sandvig, M.L. Torgersen, H.A. Raa, B. van Deurs, Clathrin-independent endocytosis: from nonexisting to an extreme degree of complexity, Histochem. Cell Biol. 129 (2008) 26776.

[22] P. Thomsen, K. Roepstorff, M. Stahlhut, B. van Deurs, Caveolae are highly immobile plasma membrane microdomains, which are not involved in constitutive endocytic trafficking, Mol. Biol. Cell. 13 (2002) 238-250.

[23] R.L. Kanasty, K.A. Whitehead, A.J. Vegas, D.G. Anderson, Action and reaction: the biological response to siRNA and its delivery vehicles, Mol. Ther. 20 (2012) 513-24. 
[24] H.M. Aliabadi, B. Landry, R.K. Bahadur, A. Neamnark, O. Suwantong, H. Uludağ, Impact of lipid substitution on assembly and delivery of siRNA by cationic polymers, Macromol. Biosci. 11 (2011) 662-72.

[25] V. Incani, A. Lavasanifar, H. Uludağ, Lipid and hydrophobic modification of cationic carriers on route to superior gene vectors, Soft Matter. 6 (2010) 2124.

[26] R.R. Sawant, S.K. Sriraman, G. Navarro, S. Biswas, R.A. Dalvi, V.P. Torchilin, Polyethyleneimine-lipid conjugate-based $\mathrm{pH}$-sensitive micellar carrier for gene delivery, Biomaterials. 33 (2012) 3942-51.

[27] W.J. Kim, C.-W. Chang, M. Lee, S.W. Kim, Efficient siRNA delivery using water soluble lipopolymer for anti-angiogenic gene therapy, J. Control. Release. 118 (2007) 357-63.

[28] G. Navarro, R.R. Sawant, S. Essex, C. Tros de Ilarduya, V.P. Torchilin, Phospholipidpolyethylenimine conjugate-based micelle-like nanoparticles for siRNA delivery, Drug Deliv. Transl. Res. 1 (2011) 25-33.

[29] G. Navarro, R.R. Sawant, S. Biswas, S. Essex, C. Tros de Ilarduya, V.P. Torchilin, Pglycoprotein silencing with siRNA delivered by DOPE-modified PEI overcomes doxorubicin resistance in breast cancer cells, Nanomedicine. 7 (2012) 65-78.

[30] Z. Dai, T. Gjetting, M.A. Mattebjerg, C. Wu, T.L. Andresen, Elucidating the interplay between DNA-condensing and free polycations in gene transfection through a mechanistic study of linear and branched PEI, Biomaterials. 32 (2011) 8626-34.

[31] Y. Yue, F. Jin, R. Deng, J. Cai, Y. Chen, M.C.M. Lin, H.-F. Kung, C. Wu, Revisit complexation between DNA and polyethylenimine - Effect of uncomplexed chains free in the solution mixture on gene transfection, J. Control. Release. 155 (2011) 67-76.

[32] Y. Yue, F. Jin, R. Deng, J. Cai, Z. Dai, M.C.M. Lin, H.-F. Kung, M.A. Mattebjerg, T.L. Andresen, $\mathrm{C}$. $\mathrm{Wu}$, Revisit complexation between DNA and polyethylenimine - Effect of length of free polycationic chains on gene transfection, J. Control. Release. 152 (2011) 14351 .

[33] J. Sambrook, D.W. Russel, Molecular Cloning: A Laboratory Manual vol. 1-3, 3rd ed., Cold Spring Harbour Laboratory Press, Cold Spring Harbour, New York, 2001.

[34] R.V. Søndergaard, J.R. Henriksen, T.L. Andresen, Design, calibration and application of 
broad-range optical nanosensors for determining intracellular pH, Nat. Protoc. 9 (2014) 2841-2858.

[35] R.V. Søndergaard, N.M. Christensen, J.R. Henriksen, E.K.P. Kumar, K. Almdal, T.L. Andresen, Facing the Design Challenges of Particle-Based Nanosensors for Metabolite Quantification in Living Cells, Chem. Rev. 115 (2015) 8344-8378.

[36] R.V. Benjaminsen, H. Sun, J.R. Henriksen, N.M. Christensen, K. Almdal, T.L. Andresen, Evaluating nanoparticle sensor design for intracellular $\mathrm{pH}$ measurements, ACS Nano. 5 (2011) 5864-73.

[37] R.V. Benjaminsen, M.A. Mattebjerg, J.R. Henriksen, S.M. Moghimi, T.L. Andresen, The possible "proton sponge" effect of polyethylenimine (PEI) does not include change in lysosomal pH, Mol. Ther. 21 (2013) 149-57.

[38] B. van Deurs, P.K. Holm, K. Sandvig, Inhibition of the vacuolar H(+)-ATPase with bafilomycin reduces delivery of internalized molecules from mature multivesicular endosomes to lysosomes in HEp-2 cells, Eur. J. Cell Biol. 69 (1996) 343-350.

[39] T. Yoshimori, A. Yamamoto, Y. Moriyama, M. Futai, Y. Tashiro, Bafilomycin A1, a specific inhibitor of vacuolar-type $\mathrm{H}+$-ATPase, inhibits acidification and protein degradation in lysosomes of cultured cells, J. Biol. Chem. 266 (1991) 17707-17712.

[40] S. Boeckle, K. von Gersdorff, S. van der Piepen, C. Culmsee, E. Wagner, M. Ogris, Purification of polyethylenimine polyplexes highlights the role of free polycations in gene transfer, J. Gene Med. 6 (2004) 1102-11.

[41] P. Erbacher, T. Bettinger, P. Belguise-Valladier, S. Zou, J.L. Coll, J.P. Behr, J.-S. Remy, Transfection and physical properties of various saccharide, poly(ethylene glycol), and antibody-derivatized polyethylenimines (PEI), J. Gene Med. 1 (1999) 210-22.

[42] S.Y. Tzeng, P.H. Yang, W.L. Grayson, J.J. Green, Synthetic poly(ester amine) and poly(amido amine) nanoparticles for efficient DNA and siRNA delivery to human endothelial cells, Int. J. Nanomedicine. 6 (2011) 3309-22.

[43] I.S. Zuhorn, U. Bakowsky, E. Polushkin, W.H. Visser, M.C.A. Stuart, J.B.F.N. Engberts, D. Hoekstra, Nonbilayer phase of lipoplex-membrane mixture determines endosomal escape of genetic cargo and transfection efficiency, Mol. Ther. 11 (2005) 801-10.

[44] M. Radwan Almofti, H. Harashima, Y. Shinohara, A. Almofti, Y. Baba, H. Kiwada, Cationic liposome-mediated gene delivery: Biophysical study and mechanism of internalization, Arch. 
Biochem. Biophys. 410 (2003) 246-253.

[45] Z. Dai, C. Wu, How Does DNA Complex with Polyethylenimine with Different Chain Lengths and Topologies in Their Aqueous Solution Mixtures?, Macromolecules. 45 (2012) 4346-4353.

[46] J. Rejman, V. Oberle, I.S. Zuhorn, D. Hoekstra, Size-dependent internalization of particles via the pathways of clathrin- and caveolae-mediated endocytosis, Biochem. J. 377 (2004) 159-69.

[47] J.J. Lu, R. Langer, J. Chen, A Novel Mechanism Is Involved in Cationic Lipid-Mediated Functional siRNA Delivery, Mol. Pharm. 6 (2009) 763-771.

[48] G. Navarro, S. Essex, R.R. Sawant, S. Biswas, D. Nagesha, S. Sridhar, C.T. de ILarduya, V.P. Torchilin, Phospholipid-modified polyethylenimine-based nanopreparations for siRNAmediated gene silencing: Implications for transfection and the role of lipid components, Nanomedicine Nanotechnology, Biol. Med. 10 (2014) 411-419.

[49] A. Utskarpen, R. Massol, B. van Deurs, S.U. Lauvrak, T. Kirchhausen, K. Sandvig, Shiga toxin increases formation of clathrin-coated pits through Syk kinase, PLoS One. 5 (2010) e10944.

[50] G. Scita, P.P. Di Fiore, The endocytic matrix, Nature. 463 (2010) 464-73.

[51] Z. Cheng, R. Singh, D. Sharma, E. Holicky, K. Hanada, D. Marks, R. Pagano, Distinct mechanisms of clathrin-independent endocytosis have unique sphingolipid requirements, Mol. Biol. Cell. 17 (2006) 3197-3210. 
Figures

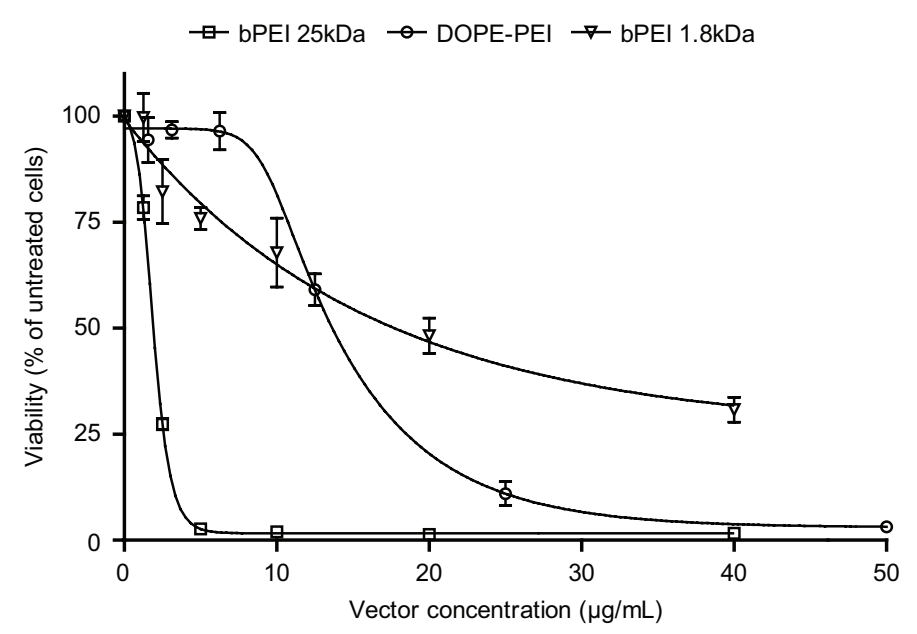

Figure 1. Cytotoxicity of vector polymers. The cells were treated with increasing concentrations of polymer for $24 \mathrm{~h}$. DOPE-PEI denotes DOPE-conjugated bPEI 1.8kDa. Results are presented as mean of triplicates \pm SD. Trend lines are 5 parameter fits. The figure is representative of three independent experiments. 

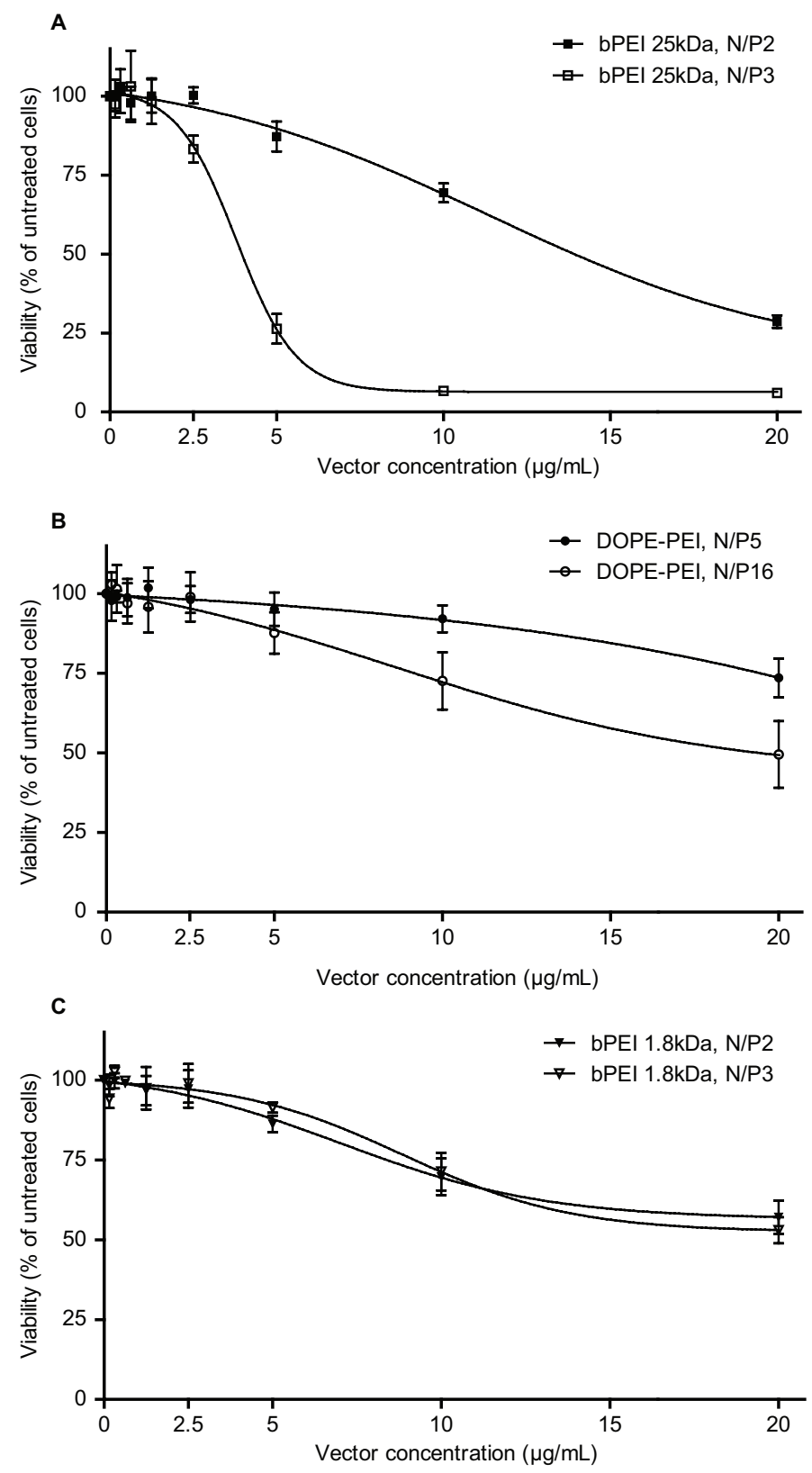

Figure 2. Cytotoxicity of polyplexes. A. bPEI 25kDa, B. DOPE-PEI, C. bPEI $1.8 \mathrm{kDa}$. The cells were treated with increasing concentrations of polymer for $24 \mathrm{~h}$. For reference, the total vector concentration in our in vitro assays at $\mathrm{N} / \mathrm{P} 3$ is $0.667 \mu \mathrm{g} / \mathrm{mL}$ (bPEI $25 \mathrm{kDa}$, bPEI $1.8 \mathrm{kDa}$ ) and 5.2 $\mu \mathrm{g} / \mathrm{mL}$ at N/P16 (DOPE-PEI). DOPE-PEI denotes DOPE-conjugated bPEI 1.8kDa. Results are presented as mean of triplicates \pm SD. Trend lines are 4 parameter fits. Representative of three independent experiments each. 


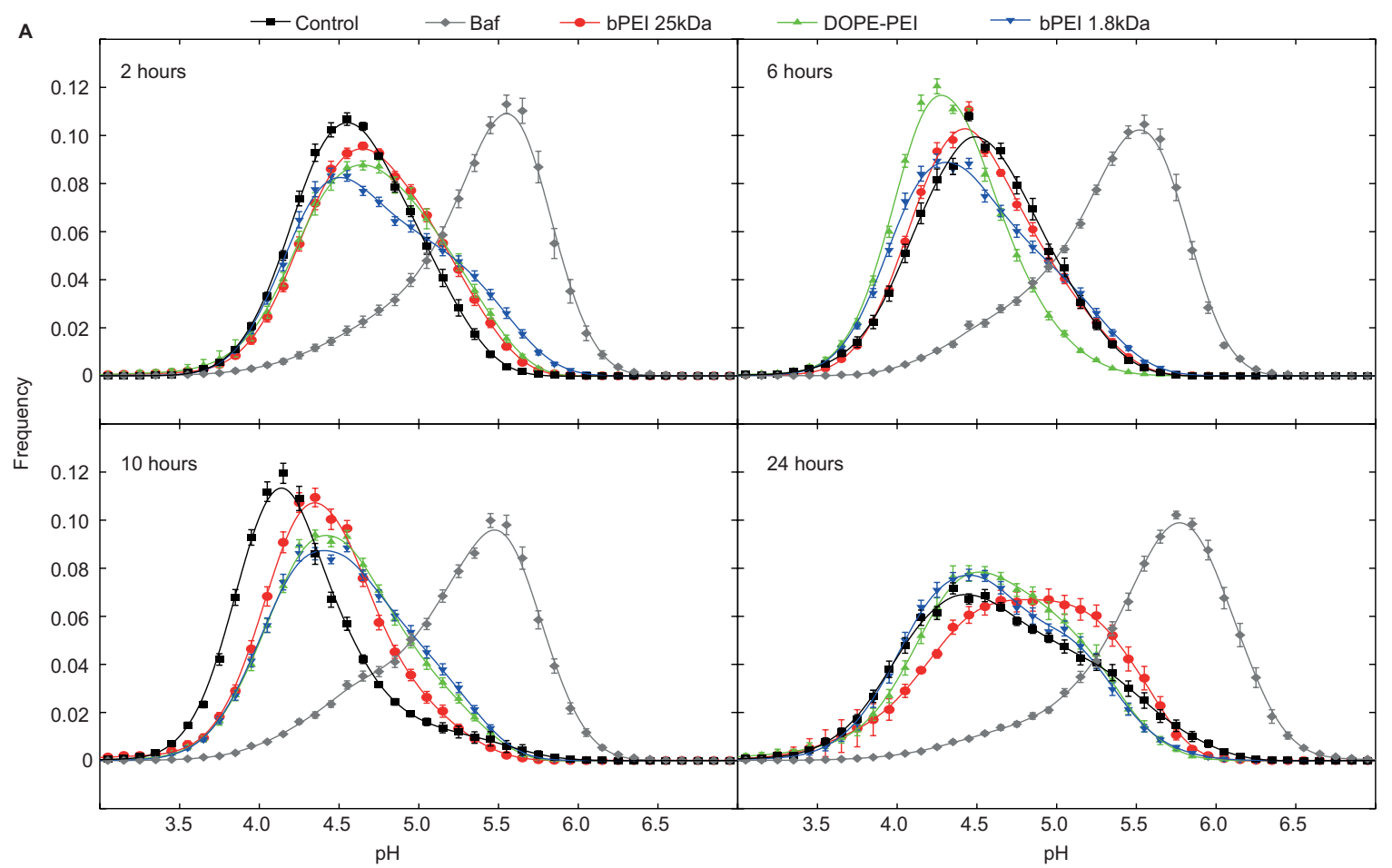

B
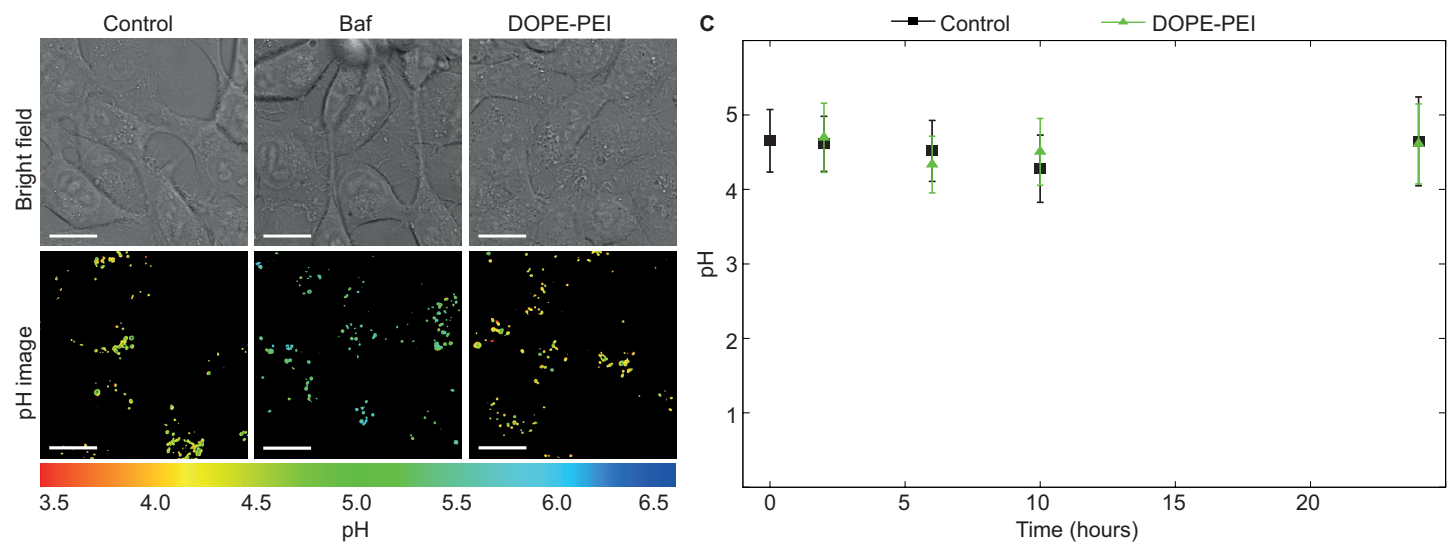

Figure 3. Lysosomal pH in response to bPEI 1.8kDa, bPEI 25kDa, DOPE-PEI or Bafilomycin A1. DOPE-PEI denotes DOPE-conjugated bPEI 1.8kDa. HT1080pLUC cells with internalized nanosensor for $16 \mathrm{~h}$ were treated with bPEI $1.8 \mathrm{kDa}$, bPEI $25 \mathrm{kDa}$ or DOPE-PEI for $6 \mathrm{~h}$ and imaged at the indicated time points. A. Histograms showing $\mathrm{pH}$ distributions of nanosensor containing cells without further treatment (Control) or treated with bPEI $25 \mathrm{kDa}$, bPEI $1.8 \mathrm{kDa}$, DOPE-PEI or Bafilomycin A1 (Baf). Bafilomycin A1 was always added 40 min prior to measurement. Data points are mean values \pm SEM. B. Representative images of cells obtained after $6 \mathrm{~h}$ of incubation. 
Top row: bright field images. Bottom row: $\mathrm{pH}$ images. The ratio of the original $\mathrm{pH}$-sensitive and reference signals was converted to $\mathrm{pH}$ via a calibration curve and images color coded according to the linear $\mathrm{pH}$ scale. No difference is observed between the control cells and the DOPE-PEI treated cells, whereas a clear change in color from yellow/green to cyan can be observed between the control cells and the Bafilomycin A1 treated cells. C. Measurements of lysosomal $\mathrm{pH}$ in response to DOPE-PEI over time compared to untreated control cells. Presented is mean $\pm \mathrm{SD}$ of the $\mathrm{pH}$ frequency distributions obtained in A. Time-point zero was collected just before addition of vector. Representative of three independent experiments.
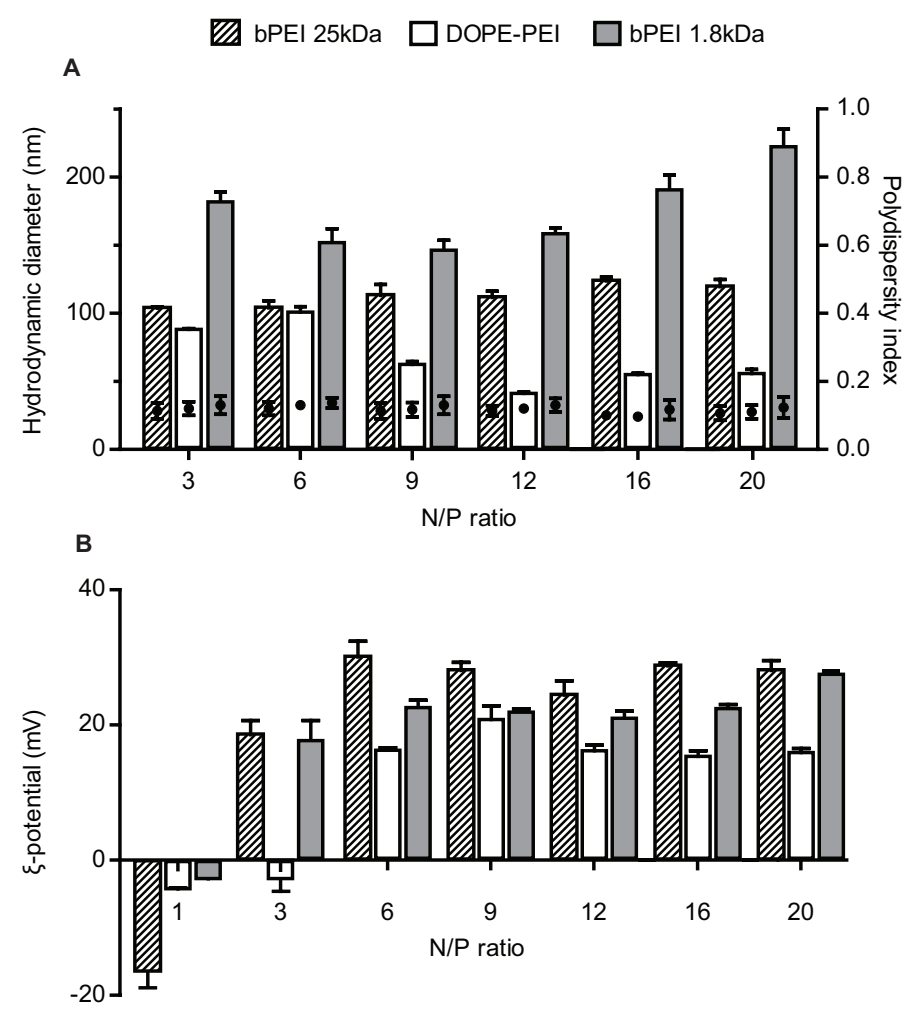

Figure 4. Size and zeta potential as a function of N/P ratio. Scatter symbols represent polydispersity for the corresponding polyplex. A. Size. B. Zeta potential. DOPE-PEI denotes DOPE-conjugated bPEI 1.8kDa. Three separate preparations per N/P ratio, error bars represent SD. 


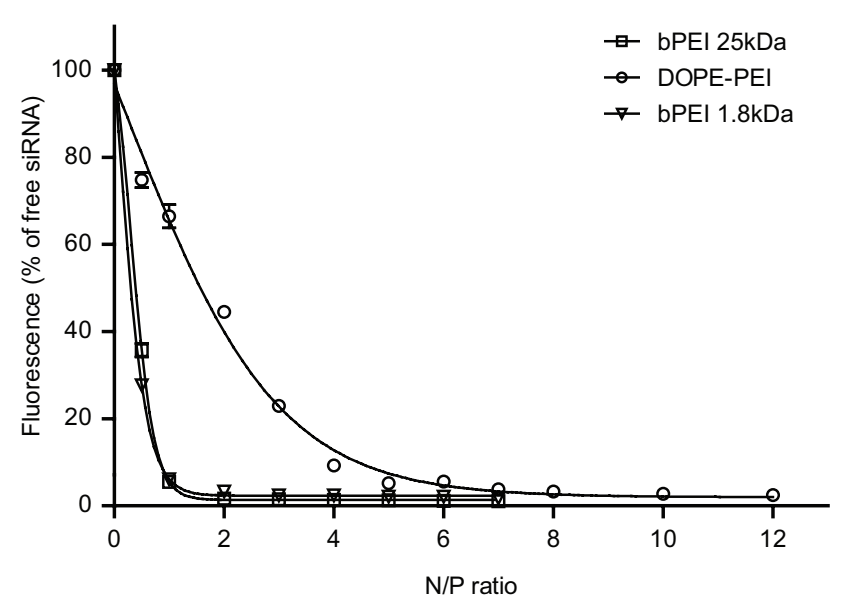

Figure 5. Condensation of siRNA by bPEI 25kDa, DOPE-PEI and bPEI $1.8 \mathrm{kDa}$. Condensation assessed by PicoGreen exclusion following addition of increasing amounts of vector to a constant amount of siRNA. The PicoGreen fluorescence intensity for siRNA in the absence of any vector was set to $100 \%$. DOPE-PEI denotes DOPE-conjugated bPEI $1.8 \mathrm{kDa}$. Results are presented as mean of triplicates \pm SD. Trend lines are 5 parameter fits. Representative of four independent experiments.

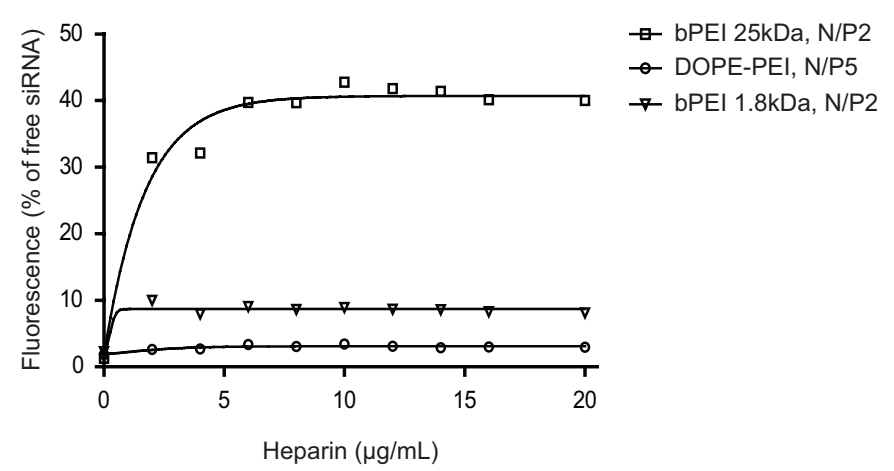

Figure 6. Heparin induced decondensation of polyplexes. Increasing amounts of sodium heparin was added to the polyplex dispersions and incubated for $30 \mathrm{~min}$ before PicoGreen assay. The PicoGreen fluorescence intensity for siRNA in the absence of any vector was set to $100 \%$. DOPEPEI denotes DOPE-conjugated bPEI 1.8kDa. Results are presented as mean of triplicates \pm SD. Trend lines are 5 parameter fits. Representative of three independent experiments. 

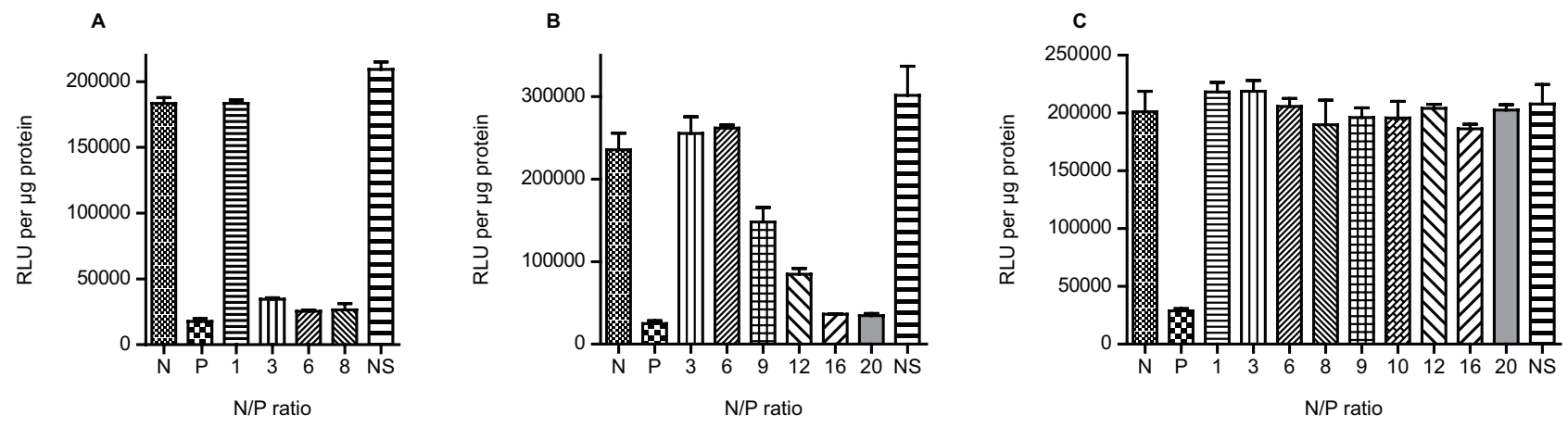

Figure 7. In vitro knockdown of luciferase expression. A: bPEI 25kDa, B: DOPE-PEI, C: bPEI 1.8kDa. $\mathrm{N}=$ Negative control cells, $\mathrm{P}=$ Positive control cells (RNAimax), $\mathrm{NS}=$ Non-sense siRNA (anti-GFP siRNA). Cells were incubated with polyplexes prepared at varying N/P ratios. RLU = relative light units and DOPE-PEI $=$ DOPE-conjugated bPEI 1.8kDa. Results are presented as mean of triplicates \pm SD. Representative of three independent experiments. 

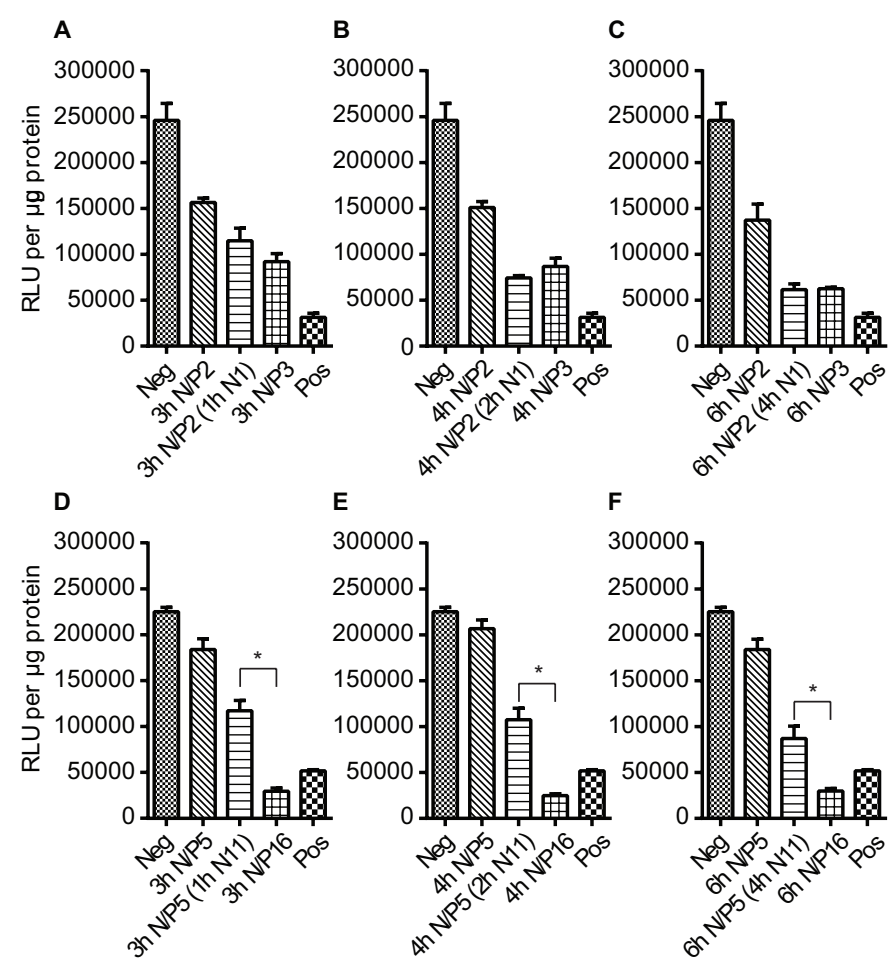

Figure 8. In vitro knockdown of luciferase expression with delayed addition of the excess fraction of vector. A-C: bPEI 25kDa, D-F: DOPE-PEI. The cells were incubated with fully condensed polyplexes for $2 \mathrm{~h}$, followed by addition of the free polymer and incubation for $1 \mathrm{~h}$ (A and D), $2 \mathrm{~h}$ (B and $\mathrm{E})$, or $4 \mathrm{~h}(\mathrm{C}$ and $\mathrm{F})$ to a total incubation time with polyplexes and polymer of 3, 4 or $6 \mathrm{~h}$. The cells were then washed and incubated to a total of $28 \mathrm{~h}$. Neg = Negative control cells, Pos $=$ Positive control cells (RNAimax). "3h N/P2" and "3h N/P5" = cells incubated for 3 h with fully condensed polyplexes - no free polymer added, " $3 \mathrm{~h} \mathrm{~N} / \mathrm{P} 3$ " and " $3 \mathrm{~h} \mathrm{~N} / \mathrm{P} 16$ " = cells incubated for $3 \mathrm{~h}$ with optimally formulated polyplexes - no free polymer added, "3h N/P2 (1h N1)" and "3h N/P5 $(1 \mathrm{~h} \mathrm{~N} 11)^{\prime \prime}=$ cell incubated for $2 \mathrm{~h}$ with fully condensed polyplexes, where after free polymer was added to a total polymer amount corresponding to optimally formulated polyplexes. RLU = relative light units and DOPE-PEI = DOPE-conjugated bPEI 1.8kDa. Results are presented as mean of triplicates \pm SD. Representative of three independent experiments. $(*)=$ significantly different by $\mathrm{t}-$ test $(\mathrm{p}<0.005)$. 


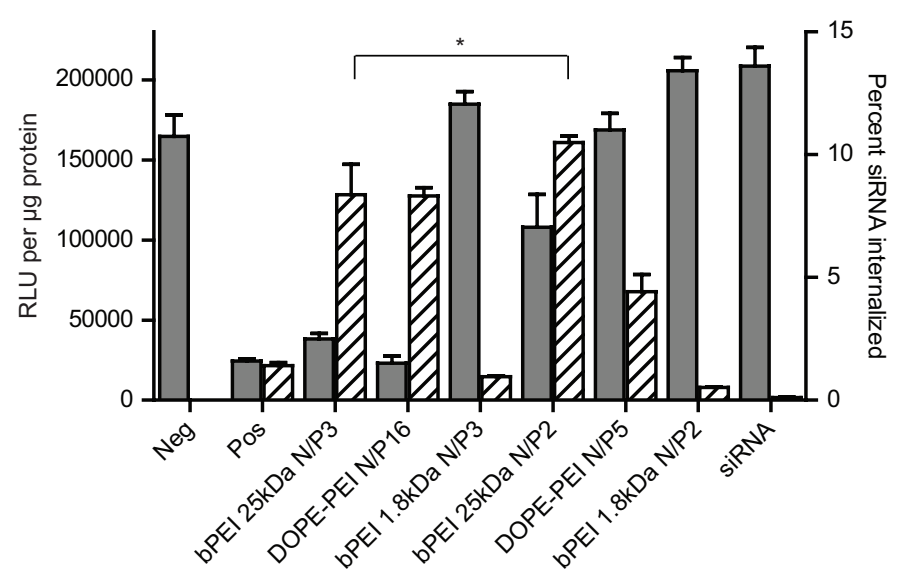

Figure 9. In vitro determination of siRNA internalization and knockdown of luciferase expression. The cells were incubated with polyplexes of the indicated $\mathrm{N} / \mathrm{P}$ ratio and analyzed for both knockdown of luciferase expression and uptake of siRNA. Neg $=$ Negative control cells, Pos $=$ Positive control cells (RNAimax), siRNA = cells incubated with siRNA in the absence of vector, RLU $=$ relative light units, and DOPE-PEI $=$ DOPE-conjugated bPEI 1.8kDa. Results are presented as mean of triplicates $\pm \mathrm{SD}$. Representative of three independent experiments. $(* *)=$ significantly different by t-test $(\mathrm{p}<0.001)$. 
Supplementary data for:

\section{Elucidating the role of free polycations in gene knockdown by siRNA polyplexes}

Thomas C. B. Klauber ${ }^{1}$, Rikke V. Søndergaard ${ }^{1}$, Rupa R. Sawant ${ }^{2}$, Vladimir P. Torchilin ${ }^{2}$, Thomas L. Andresen ${ }^{1 *}$

${ }^{1}$ DTU Nanotech, Department of Micro-and Nanotechnology, Center for Nanomedicine and Theranostics, Technical University of Denmark, Building 423, 2800 Lyngby, Denmark

${ }^{2}$ Center for Pharmaceutical Biotechnology and Nanomedicine, Northeastern University, Boston, MA 02115, USA

*Corresponding author, e-mail: tlan@nanotech.dtu.dk, Tel.: +45 4525 81 68, Fax: +45 45887762 

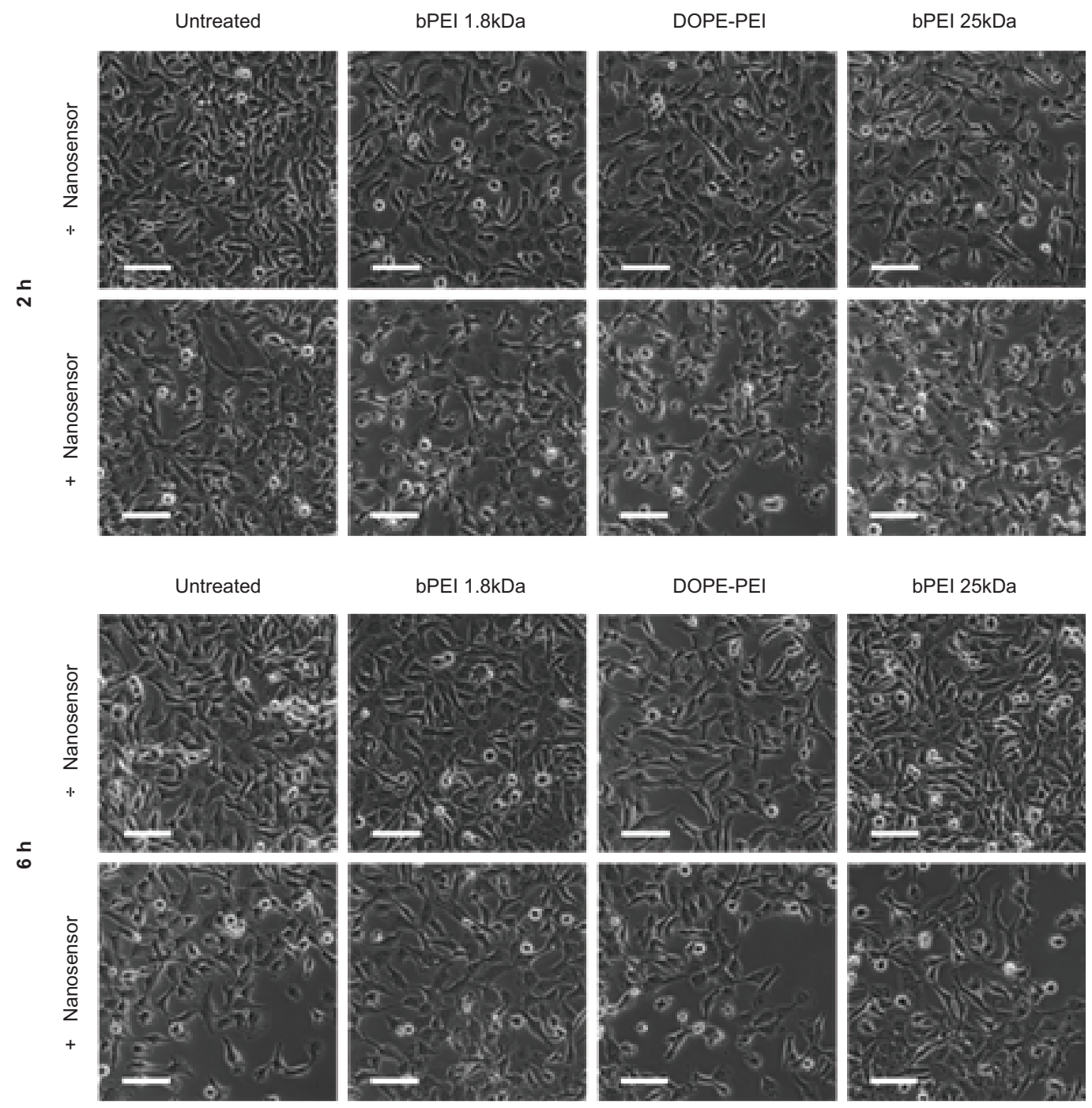

Supplementary Figure 1. Phase contrast images of HT1080pLUC cells exposed to pH-nanosensor and/or different bPEIs. HT1080 cells were either treated with nanosensor for $16 \mathrm{~h}$ (+Nanosensor) or left without nanosensor $(\div$ Nanosensor $)$ for the same time. Cells with and without nanosensor were then treated with either of the following PEIs: bPEI 1.8kDa, bPEI 25kDa or DOPE-PEI for up to 6 $\mathrm{h}$ or left untreated, followed by washing and incubation up to $24 \mathrm{~h}$. Phase contrast images were captured of the cells after 2, 6, 10 and $24 \mathrm{~h}$. Scale bars, $75 \mu \mathrm{m}$. 

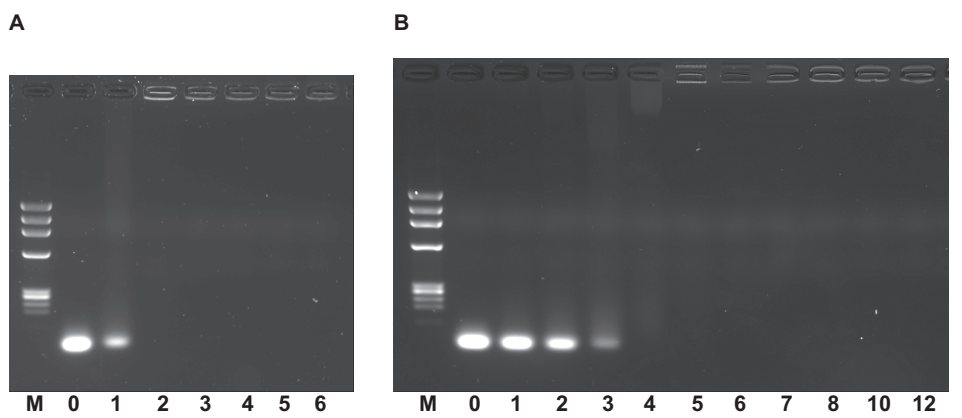

C

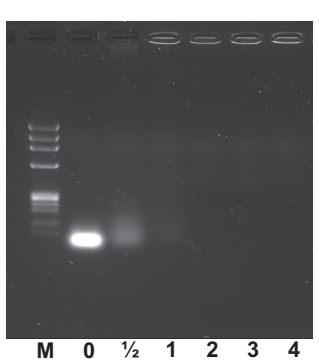

Supplementary Figure 2. Condensation of siRNA by bPEI $25 \mathrm{kDa}$ (A), DOPE-PEI (B), and PEI $1.8 \mathrm{kDa}(\mathrm{C})$, visualized by gel electrophoresis. Identical amounts of siRNA in all lanes. The numbers below the lanes refer to $\mathrm{N} / \mathrm{P}$ ratios, $0=$ free siRNA, $\mathrm{M}=\mathrm{MW}$ marker. 